\title{
Temporal trends in leisure-time sedentary behavior among adolescents aged 12-15 years from 26 countries in Asia, Africa, and the Americas
}

\author{
Mireia Felez-Nobrega ${ }^{* *}$ (D), Lauren B. Raine ${ }^{2}$, Josep Maria Haro ${ }^{1,3}$, Katrien Wijndaele ${ }^{4}$ and Ai Koyanagi ${ }^{1,3,5}$
}

\begin{abstract}
Background: Multi-country studies examining trends in sedentary behaviors among adolescents have mainly focused on high-income or Western countries, and almost no data exists for the rest of the world. Thus, this study aims to examine temporal trends in adolescents' leisure time sedentary behavior (LTSB) employing nationally representative datasets from 26 countries from five WHO-defined geographical regions.

Methods: Data from the Global School-based Student Health Survey 2003-2017 were analyzed in 17,734 adolescents [mean (SD) age: 13.7 (1.0) years; 49.0\% boys]. LTSB was self-reported and included all types of sedentary behaviors, excluding time spent at school or doing homework. The prevalence and $95 \% \mathrm{Cl}$ of high LTSB (i.e., $\geq 3 \mathrm{~h} /$ day) was calculated for the overall sample and by sex for each survey. Crude linear trends in high LTSB were assessed by linear regression models. Interaction analyses were conducted to examine differing trends among boys and girls.

Results: Temporal variations in LTSB substantially diverged across countries, with results showing increasing (6/26 countries), decreasing (4/26) and stable trends. The sharpest increases in LTSB occurred in United Arab Emirates, Kuwait, and Thailand. Some countries did not show an increase in LTSB prevalence over time but had very high levels of LTSB (i.e., > 40\%) across multiple years. Most countries showed no differences in LTSB trends between boys and girls.

Conclusions: Data from our study may serve as an important platform for policymakers, as well as local and national stakeholders, to establish country-specific and tailored strategies for reducing LTSB.
\end{abstract}

Keywords: Adolescents, Longitudinal, Cohort, Sitting, Cross-country comparison

\section{Background}

Sedentary behavior represents those behaviors undertaken while sitting or lying, with a low level of energy expenditure (i.e., $\leq 1.5$ metabolic equivalent units), excluding sleep [1]. This complex set of behaviors occurs within the context of our daily-living (e.g., work, leisure, transportation) and in different modes (e.g., reading, TV time) [1].

\footnotetext{
* Correspondence: m.felez@pssjd.org

'Research and Development Unit, Parc Sanitari Sant Joan de Déu, C/ Dr. Antoni Pujadas 42, 08830 Sant Boi de Llobregat, Barcelona, Spain Full list of author information is available at the end of the article
}

Adolescents are the most sedentary of pediatric populations, and importantly, evidence shows that they spend more than half of their after-school period in sedentary pursuits (57\%) [2]. Higher levels of sedentary behavior have been related to a wide range of negative health markers in youth including physical, behavioral and psychological outcomes. Specifically, greater time spent in sedentary behavior is related to higher depressive symptoms, unfavorable body composition, cardiovascular risk factors, poor fitness, lower self-esteem, and lower quality of life [3-6]. Importantly, those sedentary behaviors that 
occur during leisure-time may be the most important, since they have been more consistently associated with health outcomes $[4,6]$.

The steepest increases in sedentary behaviors may occur during early adolescence (9-12 years) [7], and perhaps more importantly, sedentary behavior in childhood may persist into adulthood [8], which may compromise youth's present and future health. Nonetheless, temporal trends of sedentary behavior during adolescence at the population level remain poorly described. From an international perspective, multi-country studies examining these trends have mainly focused on high-income or Western countries [9-11]. Similarly, single-country studies examining SB trends have mostly covered the same geographical regions, with the majority of evidence being derived from North American and European cohorts [12-17]. Only a few studies have examined secular changes in non-high-income countries, more specifically in Chinese, Filipino, and Brazilian adolescents [18-21].

While the existing literature is informative, there are a number of limitations that warrant further research. Available data derived solely from a single country cohort do not allow extrapolation of findings beyond the setting where the study was conducted, and the use of discrepant research designs and methodologies makes comparison between studies difficult. Multi-country studies with standardized methods across countries allow for internationally comparable estimates to better monitor trends over time among countries. However, previous multi-country studies have mostly been restricted to Western high-income countries [9-11] and studies from other settings are necessary to provide a better understanding of global sedentary behavior trends. For instance, it is possible that in low- and middleincome countries (LMICs), trends in sedentary behavior may differ from those of high-income countries due to less access to electronic devices, computers, internet or $\mathrm{TV}$, while rapid changes in these behaviors may be occurring due to accelerated urbanization processes, globalization, and changes in lifestyles [22].

Thus, the current study aimed to describe trends in leisure-time sedentary behavior (LSTB) using nationally representative data from 26 countries from five WHOdefined geographical regions (African Region, Region of the Americas, Eastern Mediterranean Region, South-East Asia Region, Western Pacific Region) for which no prior data on temporal trends of sedentary behavior among adolescents exists, with the exception of the Philippines [20]. Adolescence is a highly vulnerable period, with changes in lifestyle and environments underlying the need for a better understanding of trends in sedentary behavior, especially for the development of tailored intervention strategies and public health efforts.

\section{Methods}

Publicly available data from the Global School-based Student Health Survey (GSHS) were analyzed. Details on this survey can be found at http://www.who.int/chp/gshs and http://www.cdc.gov/gshs. Briefly, the GSHS was jointly developed by the WHO and the US Centers for Disease Control and Prevention (CDC), and other UN allies. The core aim of this survey was to assess and quantify risk and protective factors of major noncommunicable diseases. The survey draws content from the CDC Youth Risk Behavior Survey (YRBS) for which test-retest reliability has been established [23]. The survey used a standardized two-stage probability sampling design for the selection process within each participating country. For the first stage, schools were selected with probability proportional to size sampling. The second stage involved the random selection of classrooms which included students aged 13-15 years within each selected school. All students in the selected classrooms were eligible to participate in the survey regardless of age. Data collection was performed during one regular class period. The questionnaire was translated into the local language in each country and consisted of multiple choice response options; students recorded their response on computer scannable sheets. All GSHS surveys were approved, in each country, by both a national government administration (most often the Ministry of Health or Education) and an institutional review board or ethics committee. Student privacy was protected through anonymous and voluntary participation, and informed consent was obtained as appropriate from the students, parents and/or school officials. Data were weighted for non-response and probability selection.

From all publicly available data, we selected all nationally representative datasets that included the variables used in the current analysis, and countries for which data on at least two waves were available. Thus, a total of 26 countries were included in the current study. The characteristics of each country or survey are provided in Table 1. For the included countries, the survey was conducted between 2003 and 2017.

\section{Leisure-time sedentary behavior (LSTB)}

LTSB was assessed with the question "How much time do you spend during a typical or usual day sitting and watching television, playing computer games, talking with friends, or doing other sitting activities?" with answer options: $<1,1-2,3-4,5-6,7-8$, and $\geq 8$ $\mathrm{h} /$ day. This excluded time at school and when doing homework. In accordance with previous research showing that engaging in sedentary behavior for $\geq 3 \mathrm{~h} /$ day is associated with significant health risks [5, 2428 ], the variable was dichotomized as $\geq 3 \mathrm{~h} /$ day (high LTSB) or not. 
Table 1 Survey characteristics

\begin{tabular}{|c|c|c|c|c|c|}
\hline Region & Country & Country income & Year & Response rate (\%) & $N^{a}$ \\
\hline \multirow[t]{22}{*}{$\overline{A F R}$} & \multirow[t]{2}{*}{ Benin } & $\mathrm{L}$ & 2009 & 90 & 1170 \\
\hline & & $\mathrm{L}$ & 2016 & 78 & 717 \\
\hline & \multirow[t]{3}{*}{ Mauritius } & UM & 2007 & 88 & 1961 \\
\hline & & UM & 2011 & 82 & 2074 \\
\hline & & UM & 2017 & 84 & 1955 \\
\hline & \multirow[t]{2}{*}{ Namibia } & LM & 2004 & 82 & 4529 \\
\hline & & UM & 2013 & 89 & 1936 \\
\hline & \multirow[t]{2}{*}{ Seychelles } & UM & 2007 & 82 & 1154 \\
\hline & & $\mathrm{H}$ & 2015 & 82 & 2061 \\
\hline & \multirow[t]{2}{*}{ Argentina } & UM & 2007 & 77 & 1537 \\
\hline & & UM & 2012 & 71 & 21,528 \\
\hline & \multirow[t]{2}{*}{ Guatemala } & LM & 2009 & 81 & 4495 \\
\hline & & LM & 2015 & 82 & 3611 \\
\hline & \multirow[t]{2}{*}{ Guyana } & LM & 2004 & 80 & 1070 \\
\hline & & LM & 2010 & 76 & 1973 \\
\hline & \multirow[t]{2}{*}{ Suriname } & UM & 2009 & 89 & 1046 \\
\hline & & UM & 2016 & 83 & 1453 \\
\hline & \multirow[t]{3}{*}{ Trinidad \& Tobago } & $\mathrm{H}$ & 2007 & 78 & 2450 \\
\hline & & $\mathrm{H}$ & 2011 & 90 & 2363 \\
\hline & & $\mathrm{H}$ & 2017 & 89 & 2763 \\
\hline & \multirow[t]{2}{*}{ Uruguay } & UM & 2006 & 71 & 2882 \\
\hline & & $\mathrm{H}$ & 2012 & 77 & 2869 \\
\hline \multirow[t]{19}{*}{ EMR } & \multirow[t]{2}{*}{ Egypt } & LM & 2006 & 87 & 4981 \\
\hline & & LM & 2011 & 85 & 2364 \\
\hline & \multirow[t]{2}{*}{ Jordan } & LM & 2004 & 95 & 1848 \\
\hline & & LM & 2007 & 99.8 & 1648 \\
\hline & \multirow[t]{2}{*}{ Kuwait } & $\mathrm{H}$ & 2011 & 85 & 2298 \\
\hline & & $\mathrm{H}$ & 2015 & 78 & 2034 \\
\hline & \multirow[t]{2}{*}{ Lebanon } & UM & 2011 & 87 & 1982 \\
\hline & & UM & 2017 & 82 & 3347 \\
\hline & \multirow[t]{3}{*}{ Morocco } & LM & 2006 & 84 & 1986 \\
\hline & & LM & 2010 & 92 & 2405 \\
\hline & & LM & 2016 & 91 & 3975 \\
\hline & \multirow[t]{3}{*}{ Oman } & UM & 2005 & 97 & 2426 \\
\hline & & $\mathrm{H}$ & 2010 & 89 & 1000 \\
\hline & & $\mathrm{H}$ & 2015 & 92 & 1669 \\
\hline & \multirow[t]{3}{*}{ United Arab Emirates } & $\mathrm{H}$ & 2005 & 89 & 12,819 \\
\hline & & $\mathrm{H}$ & 2010 & 91 & 2302 \\
\hline & & $\mathrm{H}$ & 2016 & 80 & 3471 \\
\hline & \multirow[t]{2}{*}{ Yemen } & $L$ & 2008 & 82 & 905 \\
\hline & & LM & 2014 & 75 & 1553 \\
\hline \multirow[t]{3}{*}{ SEAR } & \multirow[t]{2}{*}{ Indonesia } & LM & 2007 & 93 & 3022 \\
\hline & & LM & 2015 & 94 & 8806 \\
\hline & Myanmar & $\mathrm{L}$ & 2007 & 95 & 2227 \\
\hline
\end{tabular}


Table 1 Survey characteristics (Continued)

\begin{tabular}{|c|c|c|c|c|c|}
\hline Region & Country & Country income & Year & Response rate (\%) & $\mathrm{N}^{\mathrm{a}}$ \\
\hline & & LM & 2016 & 86 & 2237 \\
\hline & Sri Lanka & LM & 2008 & 89 & 2504 \\
\hline & & LM & 2016 & 89 & 2254 \\
\hline & Thailand & LM & 2008 & 93 & 2675 \\
\hline & & UM & 2015 & 89 & 4132 \\
\hline \multirow[t]{10}{*}{ WPR } & Fiji & LM & 2010 & 90 & 1495 \\
\hline & & UM & 2016 & 79 & 1537 \\
\hline & Philippines & LM & 2003 & 84 & 4198 \\
\hline & & LM & 2007 & 81 & 3484 \\
\hline & & LM & 2011 & 82 & 3845 \\
\hline & & LM & 2015 & 79 & 6162 \\
\hline & Tonga & LM & 2010 & 80 & 1946 \\
\hline & & UM & 2017 & 90 & 2067 \\
\hline & Vanuatu & LM & 2011 & 72 & 852 \\
\hline & & LM & 2016 & 57 & 1288 \\
\hline
\end{tabular}

Abbreviation: AFR African Region, AMR Region of the Americas, EMR Eastern Mediterranean Region, SEAR South-East Asia Region, WPR Western Pacific Region, $H$ high income, $L$ low incomem $L M$ lower middle-income, UM upper middle-income. Income classification is based on the World Bank classification at the time of the survey

${ }^{\mathrm{a}}$ Based on sample aged $12-15$ years

\section{Statistical analysis}

Statistical analyses were performed with Stata 14.1 (Stata Corp LP, College station, Texas). The analysis was restricted to those aged $12-15$ years as most students were within this age group while information on the exact age outside of this age range was not available. The prevalence and $95 \% \mathrm{CI}$ of high LTSB (i.e., $\geq 3 \mathrm{~h}$ /day) was calculated for the overall sample and by sex for each survey year and for all the included countries. Crude linear trends in high LTSB were assessed by linear regression models across surveys within the same country to estimate regression coefficients (beta) and 95\%CI for every one-year change. P for trends were estimated using the survey year as a continuous variable. We also conducted interaction analysis to assess whether there are differing trends among boys and girls by including an interaction term (survey year $\mathrm{X}$ sex) in the model. Sampling weights and the clustered sampling design of the surveys were taken into account in all analyses.

\section{Results}

Data on 17,734 students aged $12-15$ years [mean (SD) age 13.7 (1.0) years; $49.0 \%$ boys] were used for the current analysis. The trends in sedentary behavior are shown in Table 2, Fig. 1 (overall), Fig. 2 (boys), and Fig. 3 (girls). Overall, the prevalence of high LTSB (i.e., $\geq 3 \mathrm{~h} /$ day) ranged from $9.7 \%$ in Myanmar (2007) to $62.9 \%$ in Kuwait (2015). Overall, significant increasing trends for high LTSB were observed in Namibia between 2004 (30.7\%) and 2013 (37.2\%) (beta $=0.71 ; 95 \% \mathrm{CI}=0.35,1.08)$, Uruguay between $2006(49.6 \%)$ and 2012 (58.3\%) (beta $=1.45 ; 95 \% \mathrm{CI}=0.82$,
2.08), Kuwait between 2011 (53.1\%) and 2015 (62.9\%) (beta $=2.45$; $95 \% \mathrm{CI}=0.56,4.34$ ), United Arab Emirates between $2005(38.8 \%)$ and $2016 \quad(54.7 \%) \quad($ beta $=1.41$; $95 \% \mathrm{CI}=1.01,1.81)$, Myanmar between 2007 (9.7\%) and $2016 \quad(16.2 \%) \quad($ beta $=0.73 ; \quad 95 \% \mathrm{CI}=0.35,1.10)$, and Thailand between 2008 (37.6\%) and 2015 (50.7\%) (beta = $1.86 ; 95 \% \mathrm{CI}=1.08,2.64)$. The beta can be interpreted as the average percentage point change in prevalence per year. On the other hand, significant decreasing trends were observed in Lebanon between 2011 (47.2\%) and 2017 (40.2\%) (beta $=-1.17 ; 95 \% \mathrm{CI}=-2.07,-0.28)$, Yemen between $2008(26.8 \%)$ and $2014(19.4 \%) \quad$ (beta $=-1.23$; $95 \% \mathrm{CI}=-2.24,-0.22)$, Tonga between 2010 (29.2\%) and 2017 (20.3\%) (beta $=-1.28 ; \quad 95 \% \mathrm{CI}=-1.78,-0.78)$, and Indonesia between 2007 (33.8\%) and 2015 (24.5\%) (beta $=-1.17 ; 95 \% \mathrm{CI}=-1.83,-0.51)$. The overall prevalence of LTSB was stable over time in all other countries.

Most countries showed similar trends between boys and girls, but interaction analysis showed that there were significant differences in trends by sex in Seychelles, Egypt, United Arab Emirates, and Tonga. In Seychelles, a significant decreasing trend was only observed among boys ( $b=-0.64 ; 95 \% C I=-1.15,-0.13)$ between 2007 (50.5\%) and 2015 (45.4\%), while in Egypt, a significant increasing trend was only observed among boys $(b=2.72 ; 95 \% \mathrm{CI}=1.00$, 4.44) between 2006 (22.0\%) and 2011 (35.6\%). The significant increasing trend observed in United Arab Emirates between 2005 and 2016, and the significant decreasing trend in Tonga between 2010 and 2017 were both driven mainly by the more pronounced trend among girls. 


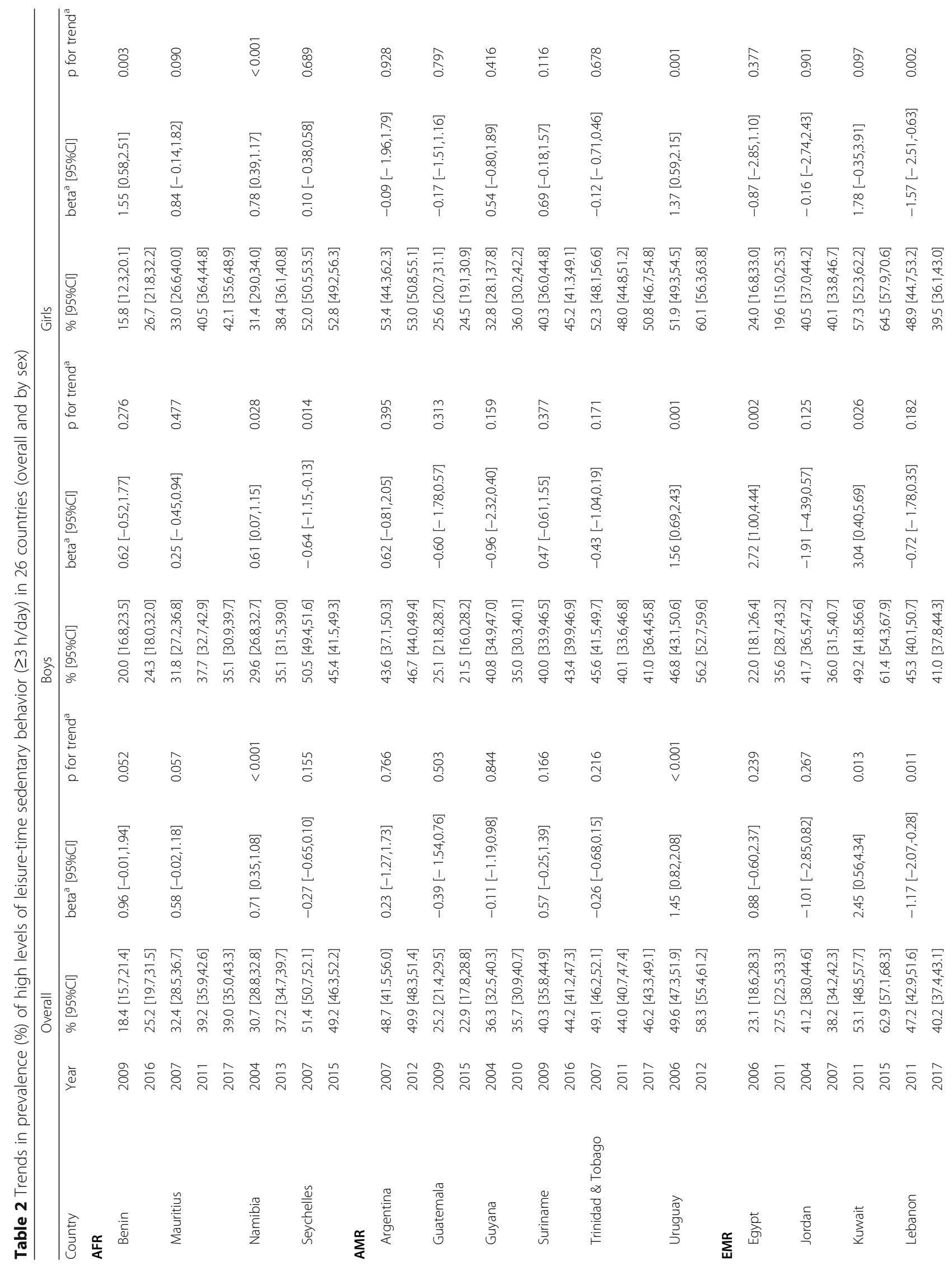




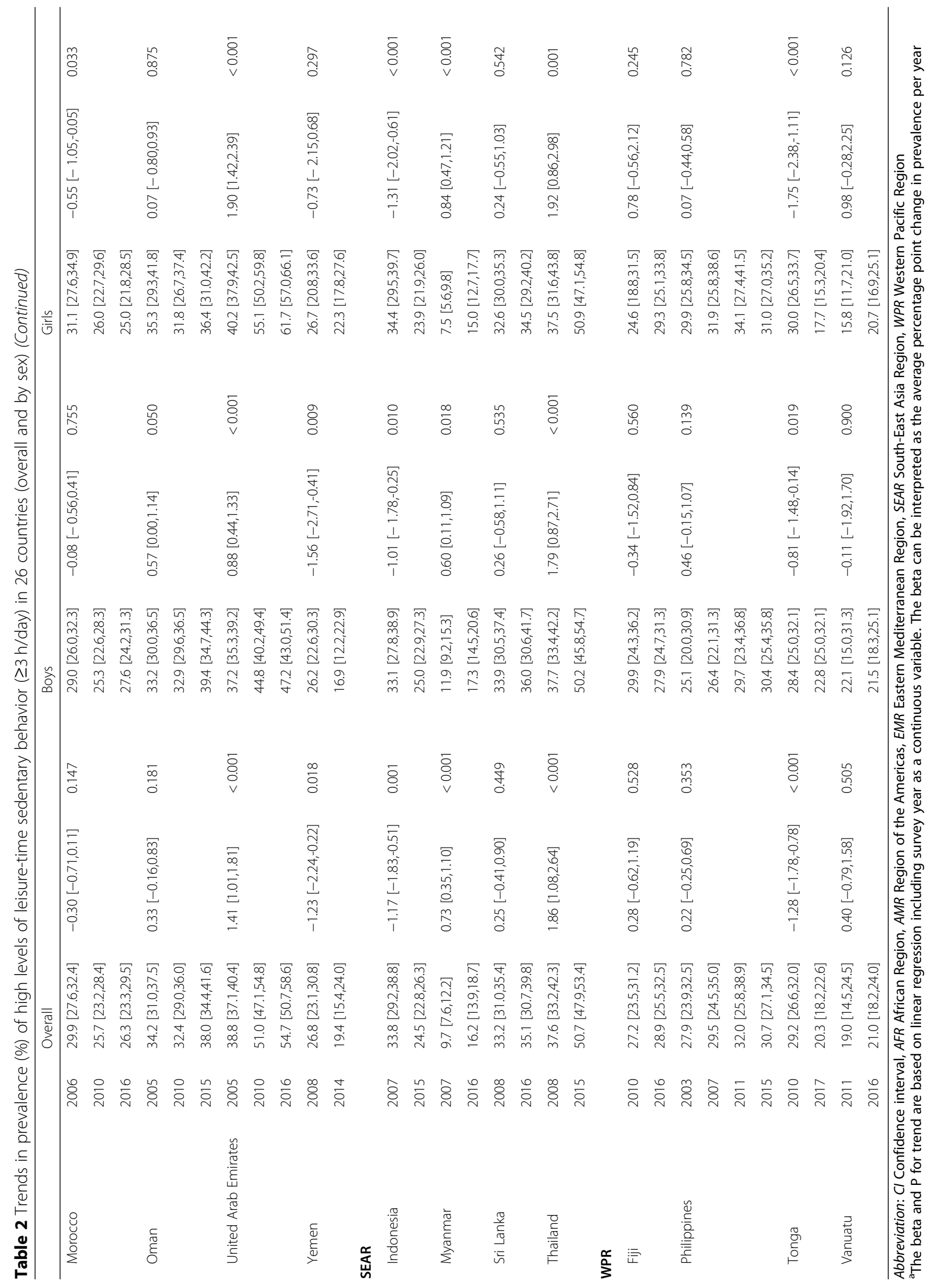


(A) African Region

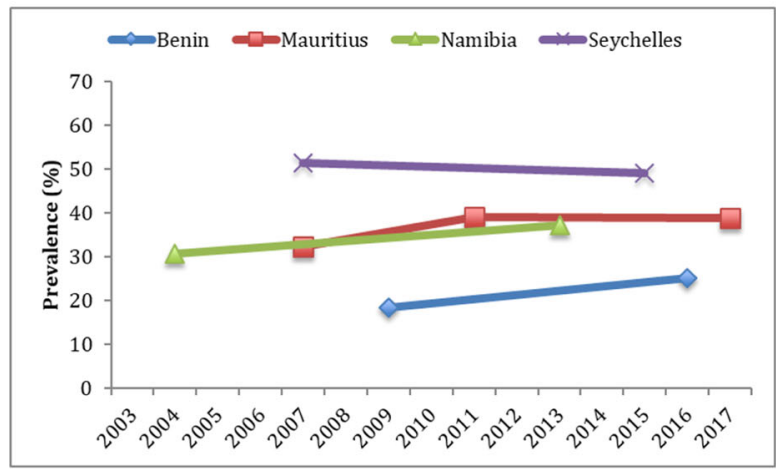

(B) Region of the Americas

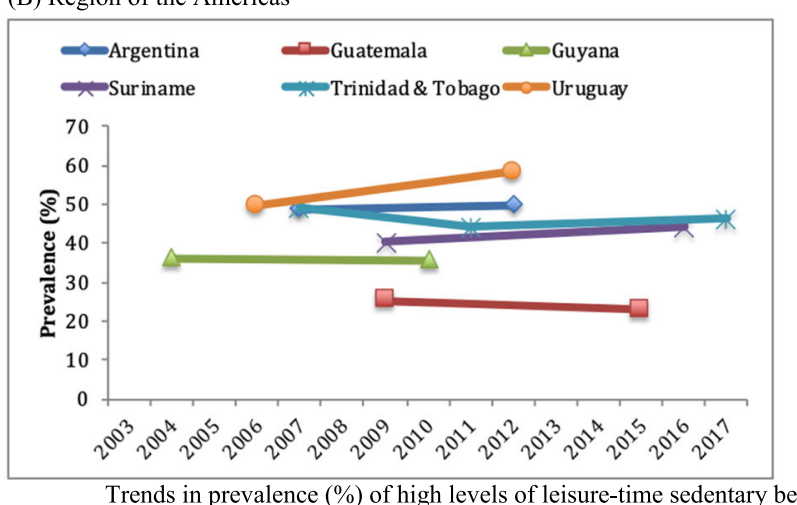

(C) Eastern Mediterranean Region

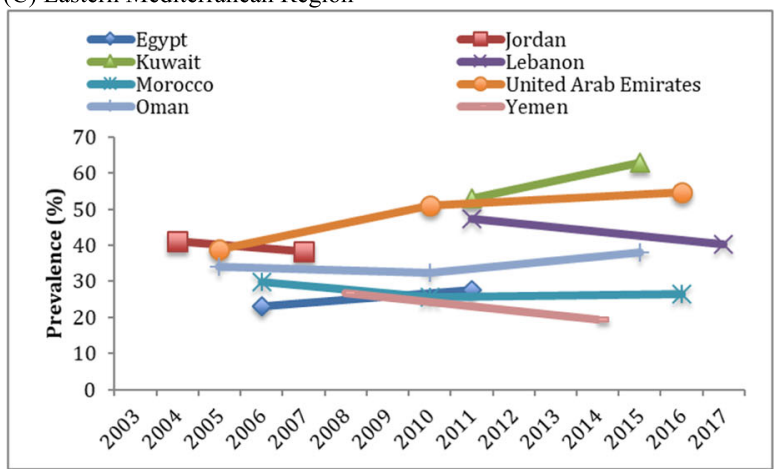

(D) South East-Asia Region \& Western Pacific Region

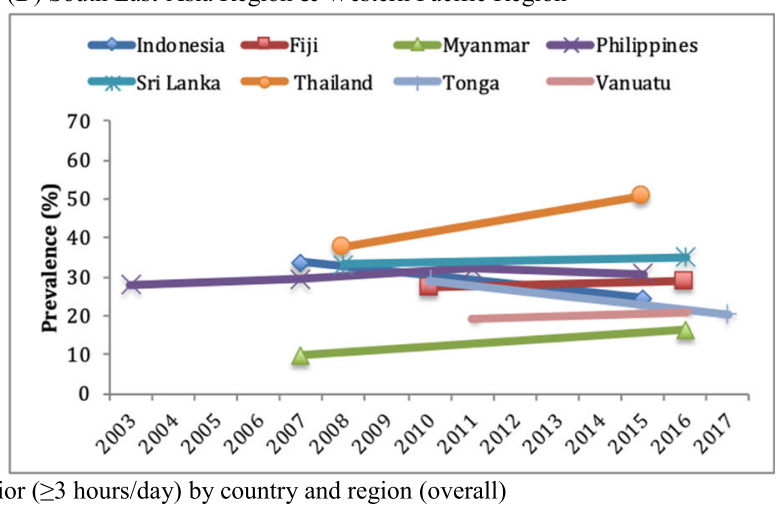

Fig. 1 Trends in prevalence (\%) of high levels of leisure-time sedentary behavior ( $\geq 3 \mathrm{~h} /$ day) by country and region (overall). a African Region. b Region of the Americas. $\mathbf{c}$ Eastern Mediterranean Region. $\mathbf{d}$ South East-Asia Region \& Western Pacific Region

\section{Discussion}

This multicounty study that examined temporal trends in adolescents' LTSB in a large population sample of 26 under-represented countries from five WHO-defined geographical regions allowed for the extension of previous research by estimating LTSB over time among adolescents in world regions where almost no data exists.

The current study found that temporal variations in LTSB substantially diverged across countries, with results showing increasing, decreasing and stable trends. Furthermore, concerningly high rates of LTSB were found for several countries. Former evidence tends to show increasing trends over time independently of method of measurement or type of sedentary behavior. For instance, single country studies found that self-reported out-of-school screen time (including or not including homework hours), increased over time in adolescents from Hong Kong, UK, Estonia and Czech Republic, and mainland China [14-16, $18,19,29]$. Additionally, a recent US study specifically showed stable prevalence for watching TV/videos and significant increases in adolescents' computer use between 2001 and 2016 [12]. Similar findings were shown in a LMIC setting where Brazilian adolescents spent less time watching TV between 2001 and 2011, whereas leisure computer use increased during the same period [21]. Beyond leisure screen time, other leisure-based sedentary behaviors (e.g., reading, writing) and time spent sedentary doing homework increased in adolescents from Mainland China and Hong Kong at different time points between 1997 and 2006 [18] and between 1995 and 2000 [29], although there were exceptions (e.g., decreasing trends in homework-related sedentary behavior among adolescents of mainland China between 2004 and 2011 [19]). Next, total sedentary time assessed via accelerometry (20132015) or via self-report (2007-2016) increased over time in Finnish and US adolescents, respectively [12, 13]. Two large multi-country studies mostly based in Western or high-income countries found that adolescents' TV viewing time decreased, while computer use (including leisure and non-leisure purposes) sharply increased over time in most included countries between 2002 and 2014 [9, 10]. Similarly, increases in total accelerometry-derived sedentary behavior (harmonized datasets from 1997 to 2014) were found in a study including adolescents from several European countries [11].

Differences in research designs and methodologies regarding the assessment of different constructs and 


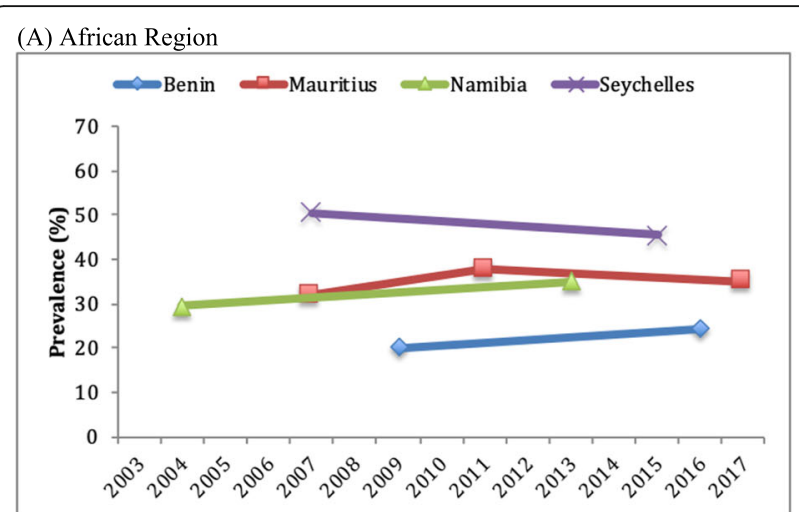

(B) Region of the Americas
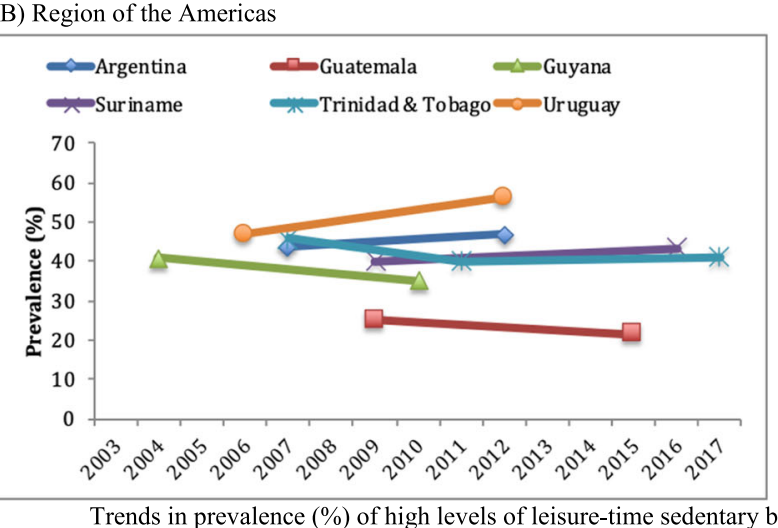

(C) Eastern Mediterranean Region

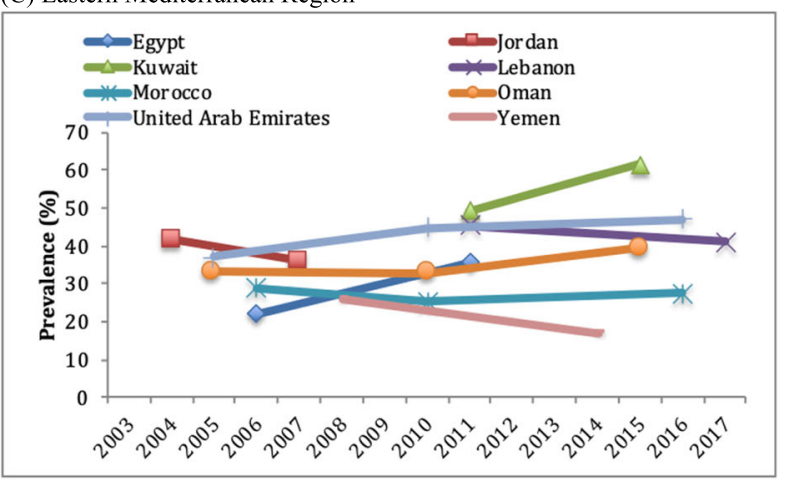

(D) South East-Asia Region \& Western Pacific Region

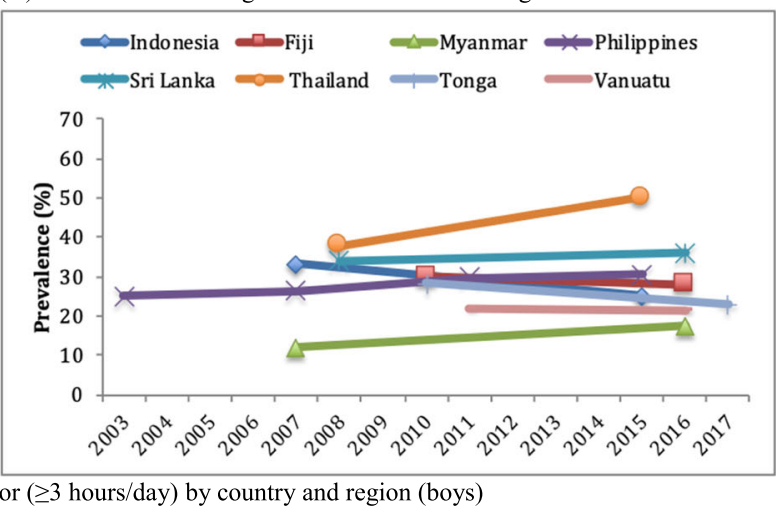

Fig. 2 Trends in prevalence (\%) of high levels of leisure-time sedentary behavior ( $\geq 3$ h/day) by country and region (boys). a African Region. b Region of the Americas. c Eastern Mediterranean Region. $\mathbf{d}$ South East-Asia Region \& Western Pacific Region

dimensions of sedentary behavior hinder comparability between our results and those from these previous studies. That is, while the present study relied on a more comprehensive definition of sedentary behavior that included all types of LTSB (i.e., screen and non-screen based), the vast majority of previous studies have assessed either TV time and computer use (including leisure and non-leisure purposes such as homework) solely or total self-reported/accelerometer-measured sedentary behavior. The only study that used a comparable measure of sedentary behavior with ours (i.e., a composite measure of LTSB including screen and nonscreen time) found that trends remained stable over time in the Philippines [20], and this concurs with our findings from this country.

The present study revealed increasing trends in LTSB in several countries across multiple regions. The sharpest increases in LTSB occurred in United Arab Emirates, Kuwait, and Thailand, countries where more than half of the adolescents (50.7-62.9\%) reported engagement in high LTSB ( $\geq 3 \mathrm{~h} /$ day) based on most recent data. Sedentary behavior is a complex behavior that is influenced by multiple determinants. In high-income countries, advances in digital technologies have created an environment that promotes higher LTSB [30], and LMICs are also following this trend owing to the rapid spread of digital technologies (e.g., internet coverage, mobile infrastructure, smartphone connections) in recent years [31,32]. For instance, it has been estimated that $3 \mathrm{G}$ coverage increased from around $60 \%$ in 2014 to more than $90 \%$ in 2018 in Indonesia [32]. Thus, the rapid increase in access to TV, computer games and overall new technologies may have contributed to the increasing trend in LTSB observed in our study. Furthermore, globalization, urbanization and changes in built environments may also be contributing to the rising trend of LTSB especially in LMICs. In some regions, modern facilities and electricity contributed to replacing physically active chores (e.g., fetching water, firewood, gardening, cattle herding) for greater time spent in LTSB such as studying, watching TV and listening to the radio [33, 34].

While several national and international guidelines for adolescents recommend to break prolonged sedentary behavior and to limit recreational screen time [35-37], to our knowledge, no large-scale intervention studies to reduce sedentary behavior have been conducted to date. Following the seminal intervention study conducted two decades ago that aimed to reduce leisure screen-time in American elementary school children [38], previous evidence, mostly derived from high-income countries, have found that interventions aimed at reducing sedentary 


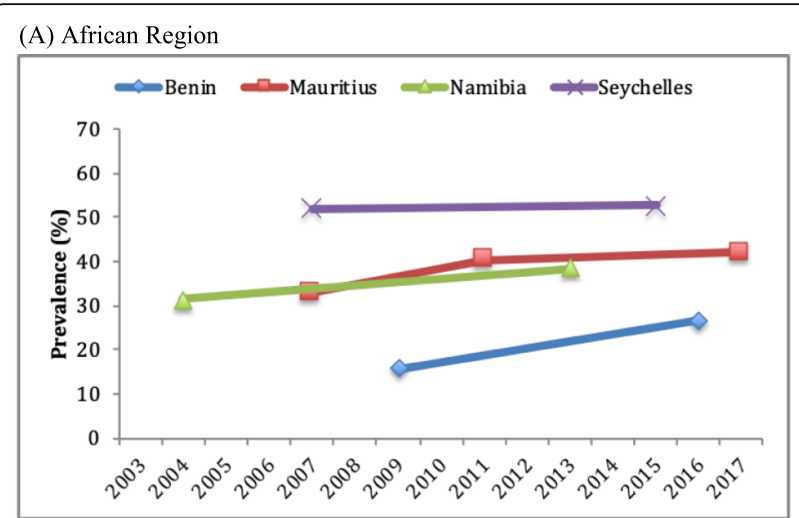

(B) Region of the Americas

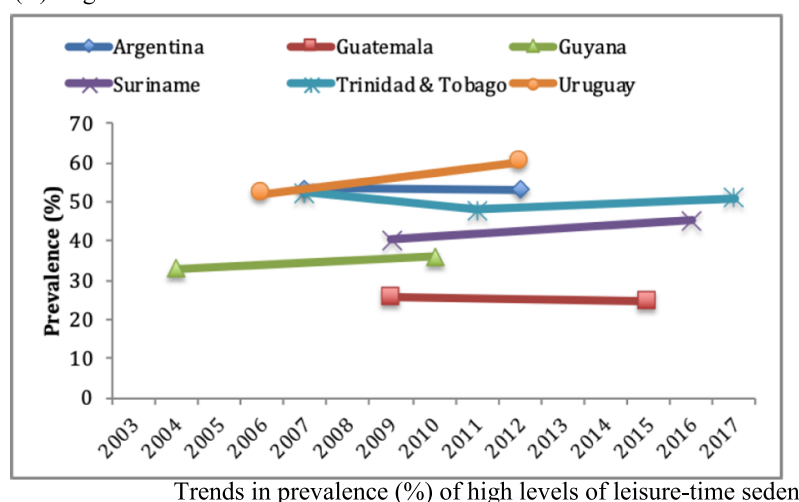

(C) Eastern Mediterranean Region

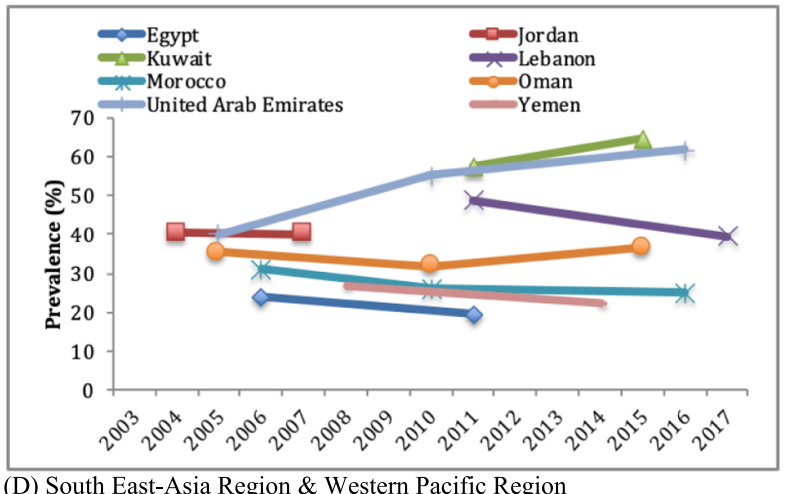

(D) South East-Asia Region \& Western Pacific Region

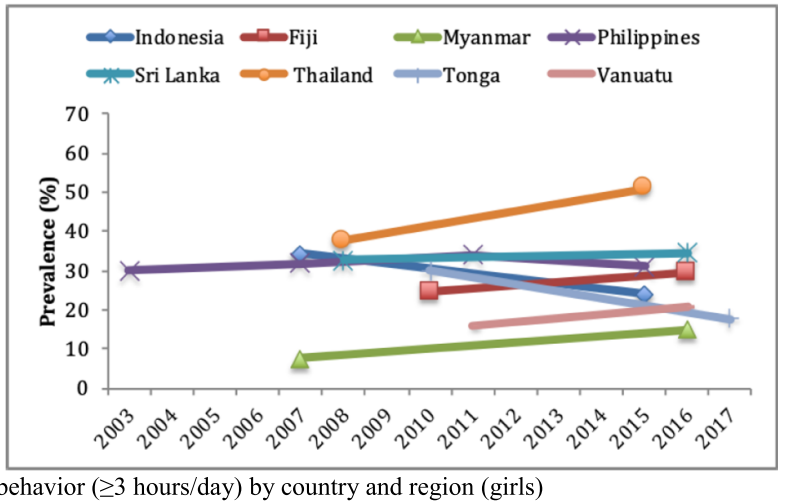

Fig. 3 Trends in prevalence (\%) of high levels of leisure-time sedentary behavior ( $\geq 3 \mathrm{~h} /$ day) by country and region (girls). a African Region. b Region of the Americas. c Eastern Mediterranean Region. d South East-Asia Region \& Western Pacific Region

behavior in young people show small but statistically significant effects [39]. Most promising strategies to reduce sedentary behavior were multi-component strategies including behavioral (e.g., focused on theory driven approaches), and environmental (e.g., aim to modify home, school, or facilities) approaches, interventions that were conducted in community settings, and those that included the involvement of family members [39, 40]. More research regarding key features or effective interventions for reducing adolescent's sedentary behavior is needed from more culturally diverse settings including LMICs. In our study, significant decreasing trends in LTSB over time were found in Lebanon, Yemen, and Tonga, and future research that aim to understand the reasons why LTSB is decreasing in some settings may provide clues on how to establish effective public health interventions to reduce sedentary behavior among adolescents.

The examination of trends in sedentary behavior by sex is crucial to determine whether behavior patterns and intervention needs are gender specific. The present study revealed that most countries showed no differences in LTSB trends between boys and girls. The evidence on sex-difference and sedentary behavior prevalence is still limited and sedentary behavior typedependent. Data from single point multi-county studies showed that accelerometry-measured total sedentary time is higher in European girls than boys [41], while another cross-national study based in Latin America and the Caribbean countries found that girls reported higher LTSB in all the eleven countries where sex-differences in LTSB were found [42]. Nonetheless, despite baseline differences, changes over time seem to occur in similar directions for boys and girls $[9,10,43]$, which is what was observed in most of the countries included in our study. However, in the current study, differences in LTSB over time between boys and girls were apparent in some countries, with the most pronounced contrast in terms of sex differences being observed in Egypt and United Arab Emirates. Specifically, boys in Egypt, and girls in United Arab Emirates showed more abrupt increases in LTSB over time compared to the opposite sex. Although the underlying reasons for these findings can only be speculated, in some Muslim-majority countries, restrictions on mobility, less access to some public spaces and less public life, factors that occur in girls' adolescence [44], may render them more sedentary. On the other hand, adolescent boys may be more likely to engage in LTSB by attending social gatherings outside of home [45]. These cultural factors may have become more widespread in some settings over the past years, but 
clearly, more research is needed to understand why there are gender differences in LTSB trends in some countries.

The strengths of the study include the large sample size and use of standardized methodology across countries which allowed direct comparisons between countries. Furthermore, we report temporal trends on LTSB from numerous countries spanning multiple continents where data were mostly non-existent. However, the study results should be interpreted in the light of several limitations. First, self-reported estimates of sedentary behavior have well-documented limitations [46]. Although large multi-country studies employing accelerometrybased measures are starting to emerge [11], the use of these tools for estimation of total sedentary behavior is currently limited to certain world regions. In addition, accelerometry measures do not provide accurate estimates of sedentary behavior, and device-based measures are unable to identify daily-living domains and modes of sedentary behavior [46-48], which may be crucial to gain insights into potential targets for intervention strategies. Hence, while methodological approaches continue to improve, self-reported measures used in our study allow direct cross-country comparisons across five different WHO-defined world regions. Another limitation of the current study is that data were restricted to those adolescents attending school, and thus, the results may not be generalizable to adolescents who do not attend school. Relatedly, it is possible that the characteristics of students that attend school have changed over the years and this may have influenced the temporal trends observed in our study. Next, surveys were conducted in different years depending on the country and thus, estimates such as average percentage point change are not totally comparable across countries. Finally, given that some countries provided more data points than others, it is possible that the temporal trends are more accurate in some countries than others.

In conclusion, this study showed that temporal variations in adolescents' LTSB do not show a consistent trend across all geographic areas, with trends increasing in six of 26 countries, decreasing in four countries, and remaining stable for the rest. Sex differences were observed only in a few countries. Some countries (e.g., Seychelles, Argentina, Suriname Trinidad \& Tobago) did not show an increase in LTSB prevalence over time but had very high levels of LTSB (i.e., > 40\%) across multiple years, highlighting the need to intervene even in countries where trends are stable. Data from our study may serve as an important platform for policymakers, as well as local and national stakeholders to establish country-specific and tailored strategies for reducing LTSB and the associated negative health outcomes in adolescents.

\section{Abbreviations}

LTSB: Leisure time sedentary behavior; LMICs: Low- and middle-income countries; GSHS: Global School-based Student Health Survey; CDC: Centers for Disease Control and Prevention; YRBS: Youth Risk Behavior Survey

\section{Acknowledgements}

This research was based on data from the Global School-Based Student Health Survey, which was made available for use by the Chronic Diseases and Health Promotion Department of the WHO and the U.S. Centers for Disease Control and Prevention.

\section{Authors' contributions}

MF and AK conceptualized the study. AK analyzed the data. MF, LR, JMH, KW, AK, interpreted the data. MF wrote the first draft of the manuscript with support from LR and AK. All authors revised the manuscript for intellectual content and approved the final manuscript.

\section{Funding}

KW was supported by the UK Medical Research Council [grant number MC_UU_12015/3]. The funding body played no role in the design of the study or the collection, analysis and interpretation of data.

\section{Availability of data and materials}

The dataset supporting the conclusions of this article is available in: http:// www.who.int/chp/gshs

\section{Ethics approval and consent to participate}

Ethical approval to conduct the study was obtained from the ethical boards at each study site. Informed consent was obtained from all participants.

\section{Consent for publication}

Not applicable.

\section{Competing interests}

The authors declare that they have no competing interests.

\section{Author details}

${ }^{1}$ Research and Development Unit, Parc Sanitari Sant Joan de Déu, C/ Dr. Antoni Pujadas 42, 08830 Sant Boi de Llobregat, Barcelona, Spain. ${ }^{2}$ Department of Psychology, Northeastern University, 125 NI, 360 Huntington Ave, Boston, MA 02115, USA. ${ }^{3}$ Centre for Biomedical Research on Mental Health (CIBERSAM), Madrid, Spain. ${ }^{4}$ MRC Epidemiology Unit, University of Cambridge, Cambridge, UK. ${ }^{5}$ ICREA, Pg. Lluis Companys 23, Barcelona, Spain.

Received: 5 June 2020 Accepted: 3 August 2020

Published online: 12 August 2020

\section{References}

1. Tremblay M. Letter to the editor: Standardized use of the terms "sedentary" and "sedentary behaviours". Appl Physiol Nutr Metab. 2012;37:540-2.

2. Arundell $L$, Fletcher $E$, Salmon J, Veitch J, Hinkley T. A systematic review of the prevalence of sedentary behavior during the after-school period among children aged 5-18 years. Int J Behav Nutr Phys Act. 2016;13(1):93.

3. Gopinath B, Hardy LL, Baur LA, Burlutsky G, Mitchell P. Physical activity and sedentary behaviors and health-related quality of life in adolescents. Pediatrics. 2012;130:167.

4. Carson V, Hunter S, Kuzik N, Gray CE, Poitras VJ, Chaput J-P, et al. Systematic review of sedentary behaviour and health indicators in school-aged children and youth: an update 1. Appl Physiol Nutr Metab. 2016:41:240-65.

5. Vancampfort D, Stubbs B, Firth J, Van Damme T, Koyanagi A. Sedentary behavior and depressive symptoms among 67,077 adolescents aged 12-15 years from 30 low- and middle-income countries. Int J Behav Nutr Phys Act. 2018;15(1):1-9.

6. van Ekris E, Altenburg TM, Singh AS, Proper Kl, Heymans MW, Chinapaw MJM. An evidence-update on the prospective relationship between childhood sedentary behaviour and biomedical health indicators: a systematic review and meta-analysis. Obes Rev. 2016;17:833-49.

7. Janssen X, Mann KD, Basterfield L, Parkinson KN, Pearce MS, Reilly JK, et al. Development of sedentary behavior across childhood and adolescence: longitudinal analysis of the Gateshead millennium study. Int J Behav Nutr Phys Act. 2016;13:88 
8. Biddle SJH, Pearson N, Ross GM, Braithwaite R. Tracking of sedentary behaviours of young people: a systematic review. Prev Med. 2010;51:345-51.

9. Bucksch J, Sigmundova D, Hamrik Z, Troped PJ, Melkevik O, Ahluwalia N, et al. International trends in adolescent screen-time behaviors from 2002 to 2010. J Adolesc Health. 2016;58:417-25.

10. World Health Organization. Adolescent obesity and related behaviours: trends and inequalities in the WHO European Region, 2002-2014: World Health Organization. Regional Office for Europe.; 2017. http://www.euro. who.int/_data/assets/pdf_file/0019/339211/WHO_ObesityReport_2017_v3. pdf. Accessed 1 May 2020.

11. Steene-Johannessen J, Hansen BH, Dalene KE, Kolle E, Northstone K, Møller NC, et al. Variations in accelerometry measured physical activity and sedentary time across Europe-harmonized analyses of 47,497 children and adolescents. Int J Behav Nutr Phys Act. 2020;17:38.

12. Yang $L$, Cao $C$, Kantor ED, Nguyen LH, Zheng $X$, Park Y, et al. Trends in sedentary behavior among the US population, 2001-2016. JAMA. 2019;321: 1587-97.

13. Kallio J, Hakonen H, Syväoja H, Kulmala J, Kankaanpää A, Ekelund U, et al. Changes in physical activity and sedentary time during adolescence: gender differences during weekdays and weekend days. Scand J Med Sci Sports. 2020;30:1265-75

14. Raudsepp L, Neissaar I, Kull M. Longitudinal stability of sedentary behaviors and physical activity during early adolescence. Pediatr Exerc Sci. 2008;20: 251-62.

15. Brodersen NH, Steptoe A, Boniface DR, Wardle J. Trends in physical activity and sedentary behaviour in adolescence: ethnic and socioeconomic differences. Br J Sports Med. 2007:41:140-4.

16. Sigmundova D, Sigmund E. Hamrik, Kalman, M. trends of overweight and obesity, physical activity and sedentary behaviour in Czech schoolchildren: HBSC study. Eur J Pub Health. 2014;24:210-5.

17. Øverby NC, Klepp Kl, Bere E. Changes in screen time activity in Norwegian children from 2001 to 2008: two cross sectional studies. BMC Public Health. 2013;13:80.

18. Cui Z, Hardy LL, Dibley MJ, Bauman A. Temporal trends and recent correlates in sedentary behaviours in Chinese children. Int J Behav Nutr Phys Act. 2011;8:93.

19. Dearth-Wesley T, Howard AG, Wang H, Zhang B, Popkin BM. Trends in domain-specific physical activity and sedentary behaviors among Chinese school children, 2004-2011. Int J Behav Nutr Phys Act. 2017;14.

20. Peltzer K, Pengid S. Health risk behaviour among in-school adolescents in the philippines: Trends between 2003, 2007 and 2011, a cross-sectional study. Int J Environ Res Public Health. 2015;13:73.

21. Silva KS, da Silva LA, Dumith SC, Garcia LMT, Bezerra J, Nahas MV. Changes in television viewing and computers/videogames use among high school students in southern Brazil between 2001 and 2011. Int J Public Health. 2014:59:77-86

22. Pew Research Center, 2016, Smartphone ownership and internet usage continues to climb in emerging economies https://www.pewresearch.org/ global/2016/02/22/smartphone-ownership-and-internet-usage-continues-toclimb-in-emerging-economies/. Accessed 6 May 2020.

23. Brener ND, Collins JL, Kann L, Warren CW, Williams BI. Reliability of the youth risk behavior survey questionnaire. Am J Epidemiol. 1995;141:575-80.

24. Vancampfort D, Firth J, Smith L, Stubbs B, Rosenbaum S, Van Damme T, et al. Cannabis use and leisure-time sedentary behavior among 94,035 adolescents aged 12-15 years from 24 low- and middle-income countries. Addict Behav. 2019;99:106104.

25. Ashdown-Franks G, Vancampfort D, Firth J, Smith L, Sabiston CM, Stubbs B, et al. Association of leisure-time sedentary behavior with fast food and carbonated soft drink consumption among 133,555 adolescents aged 12-15 years in 44 low- and middle-income countries. Int J Behav Nutr Phys Act. 2019;16:1.

26. Vancampfort D, Ashdown-Franks G, Smith L, Firth J, Van Damme T, Christiaansen $L$, et al. Leisure-time sedentary behavior and loneliness among 148,045 adolescents aged 12-15 years from 52 low- and middle-income countries. J Affect Disord. 2019;251:149-55.

27. Vancampfort D, Van Damme T, Stubbs B, Smith L, Firth J, Hallgren M, et al. Sedentary behavior and anxiety-induced sleep disturbance among 181,093 adolescents from 67 countries: a global perspective. Sleep Med. 2019;58:1926.

28. Ashdown-Franks G, Vancampfort D, Firth J, Veronese N, Jackson SE, Smith L, et al. Leisure-time sedentary behavior and obesity among 116,762 adolescents aged 12-15 years from 41 low- and middle-income countries. Obesity. 2019;27:830-6.

29. Mak KK, Day JR. Secular trends of sports participation, sedentary activity and physical self-perceptions in Hong Kong adolescents, 1995-2000. Acta Paediatr. 2010;99:1731-4

30. Griffiths MD. Trends in technological advance: implications for sedentary behaviour and obesity in screenagers. Ed Health. 2010;28:35-8.

31. United Nations Conference on Trade and Development. https://unctad.org/ en/PublicationsLibrary/der2019_en.pdf. Accessed 20 May 2020.

32. Connected Society. The state of Mobile internet connectivity. GSMA. https:// www.gsma.com/mobilefordevelopment/wp-content/uploads/2019/07/ GSMA-State-of-Mobile-Internet-Connectivity-Report-2019.pdf. Accessed 20 May 2020

33. Ojiambo RM, Easton C, Casajús JA, Konstabel K, Reilly JJ, Pitsiladis Y. Effect of urbanization on objectively measured physical activity levels, sedentary time, and indices of adiposity in Kenyan adolescents. J Phys Act Health. 2012;9:115-23.

34. Muthuri SK, Wachira LJM, Leblanc AG, Francis CE, Sampson M, Onywera VO, et al. Temporal trends and correlates of physical activity, sedentary behaviour, and physical fitness among school-aged children in sub-Saharan Africa: a systematic review. Int J Environ Res Public Health. 2014;11:3327-59.

35. Piercy KL, Troiano RP, Ballard RM, Carlson SA, Fulton JE, Galuska DA, et al. The physical activity guidelines for Americans. JAMA. 2018;320:2020-8.

36. World Health Organization. Global recommendations on physical activity for health. Geneva: World Health Organization; 2010. https://www.who.int/ dietphysicalactivity/factsheet_adults/en/. Accessed 2 Feb 2020.

37. The Department of Health. Australia's Physical Activity and Sedentary Behaviour Guidelines and the Australian 24-Hour Movement Guidelines. https://www1.health.gov.au/internet/main/publishing.nsf/Content/healthpubhlth-strateg-phys-act-guidelines\#npa517. Accessed 2 Feb 2020.

38. Robinson TN. Reducing children's television viewing to prevent obesity: a randomized controlled trial. JAMA. 1999;282(16):1561-7.

39. Biddle SJH, Petrolini I, Pearson N. Interventions designed to reduce sedentary behaviours in young people: a review of reviews. Br J Sports Med. 2014;48:182-6.

40. Blackburn NE, Wilson JJ, McMullan II, Caserotti P, Giné-Garriga M, Wirth K, et al. The effectiveness and complexity of interventions targeting sedentary behaviour across the lifespan: a systematic review and meta-analysis. Int J Behav Nutr Phys Act. 2020;17:1-18.

41. Cooper AR, Goodman A, Page AS, Sherar LB, Esliger DW, van Sluijs EMF, et al. Objectively measured physical activity and sedentary time in youth: The International children's accelerometry database (ICAD). Int J Behav Nutr Phys Act. 2015;12:113.

42. Aguilar-Farias N, Martino-Fuentealba P, Carcamo-Oyarzun J, Cortinez-O'Ryan A, Cristi-Montero C, Von Oetinger A, et al. A regional vision of physical activity, sedentary behaviour and physical education in adolescents from Latin America and the Caribbean: results from 26 countries. Int J Epidemiol. 2018:47:976-86

43. Pearson N, Haycraft E, Johnston JP, Atkin AJ. Sedentary behaviour across the primary-secondary school transition: a systematic review. Prev Med. 2017;94: 40-7.

44. Russell A, Coughlin C, El Walily M, Al AM. Youth in the United Arab Emirates: perceptions of problems and needs for a successful transition to adulthood. Int J Adolesc Youth. 2005;12:189-212.

45. Mensch BS, Ibrahim BL, Lee SM, El-Gibaly O. Gender-role attitudes among Egyptian adolescents. Stud Fam Plan. 2003;34:8-18.

46. Atkin AJ, Gorely T, Clemes SA, Yates T, Edwardson C, Brage S, et al. Methods of measurement in epidemiology: sedentary behaviour. Int J Epidemiol. 2012;41:1460-71.

47. Byrom B, Stratton G, Mc Carthy M, Muehlhausen W. Objective measurement of sedentary behaviour using accelerometers. Int J Obes. 2016:40:1-15.

48. Prince SA, Cardilli L, Reed JL, Saunders TJ, Kite C, Douillette K, et al. A comparison of self-reported and device measured sedentary behaviour in adults: a systematic review and meta-analysis. Int J Behav Nutr Phys Act. 2020;17(1):1-17

\section{Publisher's Note}

Springer Nature remains neutral with regard to jurisdictional claims in published maps and institutional affiliations. 